Erratum

\title{
Erratum to "Fluoroscopy Assisted Minimally Invasive Transplantation of Allogenic Mesenchymal Stromal Cells Embedded in HyStem Reduces the Progression of Nucleus Pulposus Degeneration in the Damaged Intervertebral Disc: A Preliminary Study in Rabbits"
}

\author{
Rifa Aquidah Subhan, ${ }^{1}$ Puvanan Karunanithi, ${ }^{1}$ Murali Malliga Raman, ${ }^{1}$ \\ Balaji Raghavendran Hanumantha Rao, ${ }^{1}$ Shani Samuel, ${ }^{1}$ Basri Johan Jeet Abdullah, ${ }^{2}$ \\ Azlina Amir Abbas, ${ }^{1}$ Jamal Azmi Mohamed, ${ }^{1}$ and Tunku Kamarul ${ }^{1}$ \\ ${ }^{1}$ Tissue Engineering Group, NOCERAL, Department of Orthopaedic Surgery, Faculty of Medicine, University of Malaya, \\ 50603 Kuala Lumpur, Malaysia \\ ${ }^{2}$ Department of Biomedical Imaging, Faculty of Medicine Building, University of Malaya, 50603 Kuala Lumpur, Malaysia \\ Correspondence should be addressed to Puvanan Karunanithi; puviee@yahoo.com \\ Received 30 May 2014; Accepted 24 June 2014; Published 24 July 2014 \\ Copyright (C) 2014 Rifa Aquidah Subhan et al. This is an open access article distributed under the Creative Commons Attribution \\ License, which permits unrestricted use, distribution, and reproduction in any medium, provided the original work is properly \\ cited.
}

\footnotetext{
"Interverbal" is corrected to be "Intervertebral" in the main title.

Basri Johan Jeet Abdullah is added to the Authors' Contribution section as follows: Basri Johan Jeet Abdullah, Murali Malliga Raman, Shani Samuel, and Balaji Raghavendran Hanumantha Rao performed scoring systems and image analyses.
} 


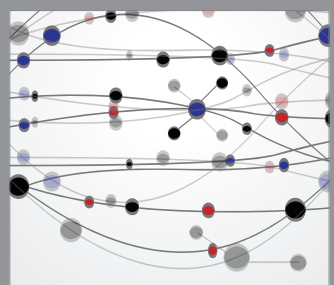

The Scientific World Journal
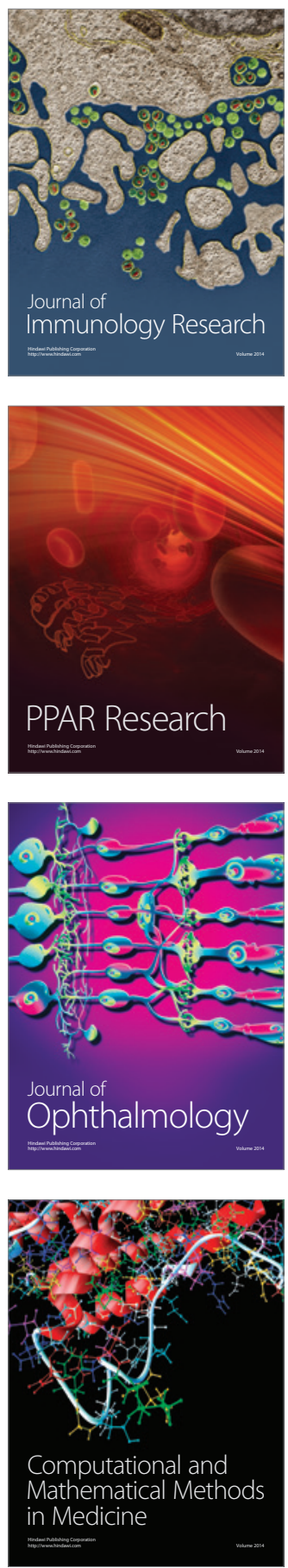

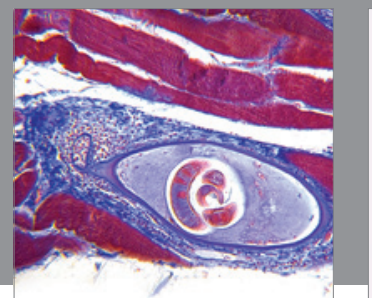

Gastroenterology

Research and Practice
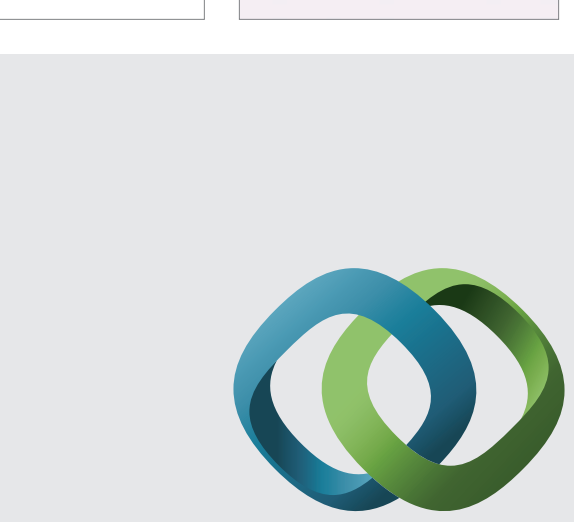

\section{Hindawi}

Submit your manuscripts at

http://www.hindawi.com
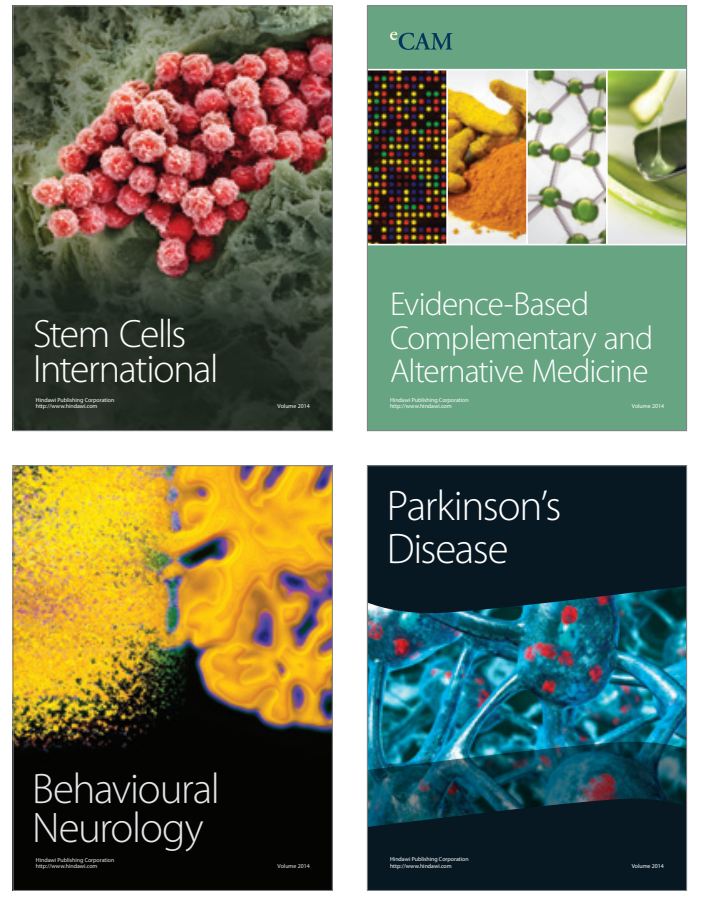
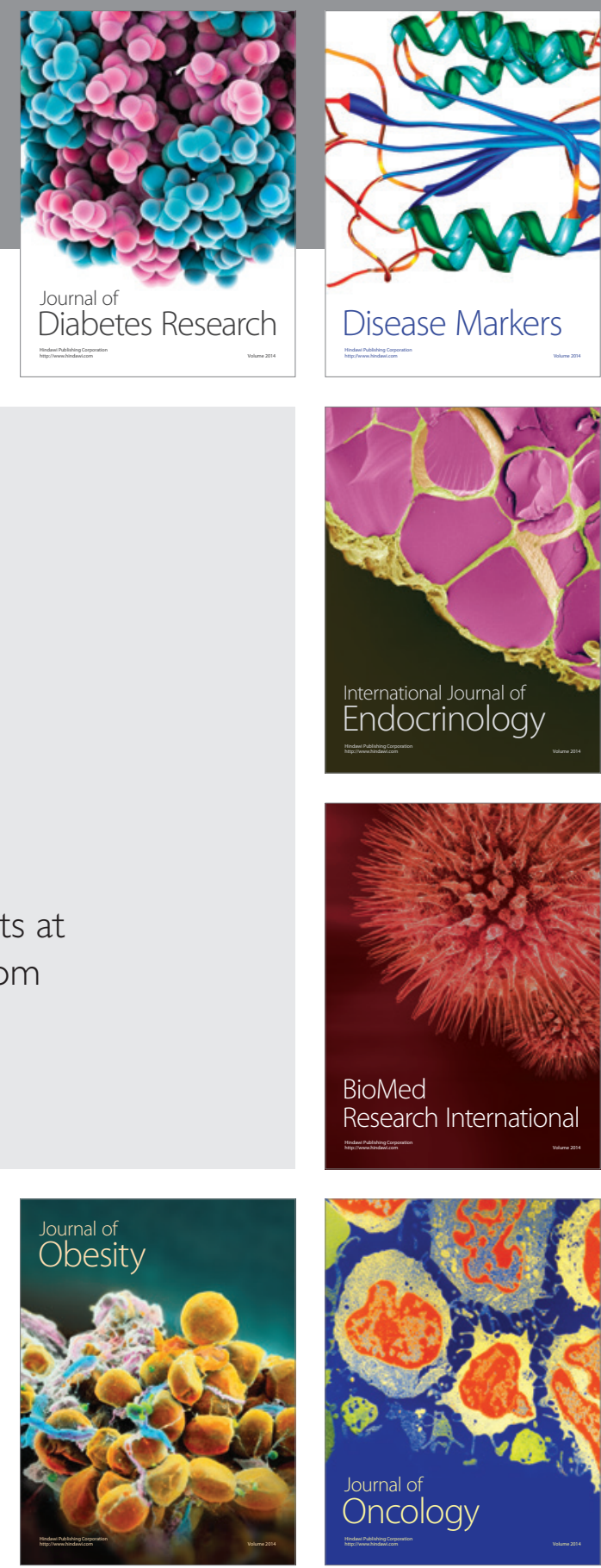

Disease Markers
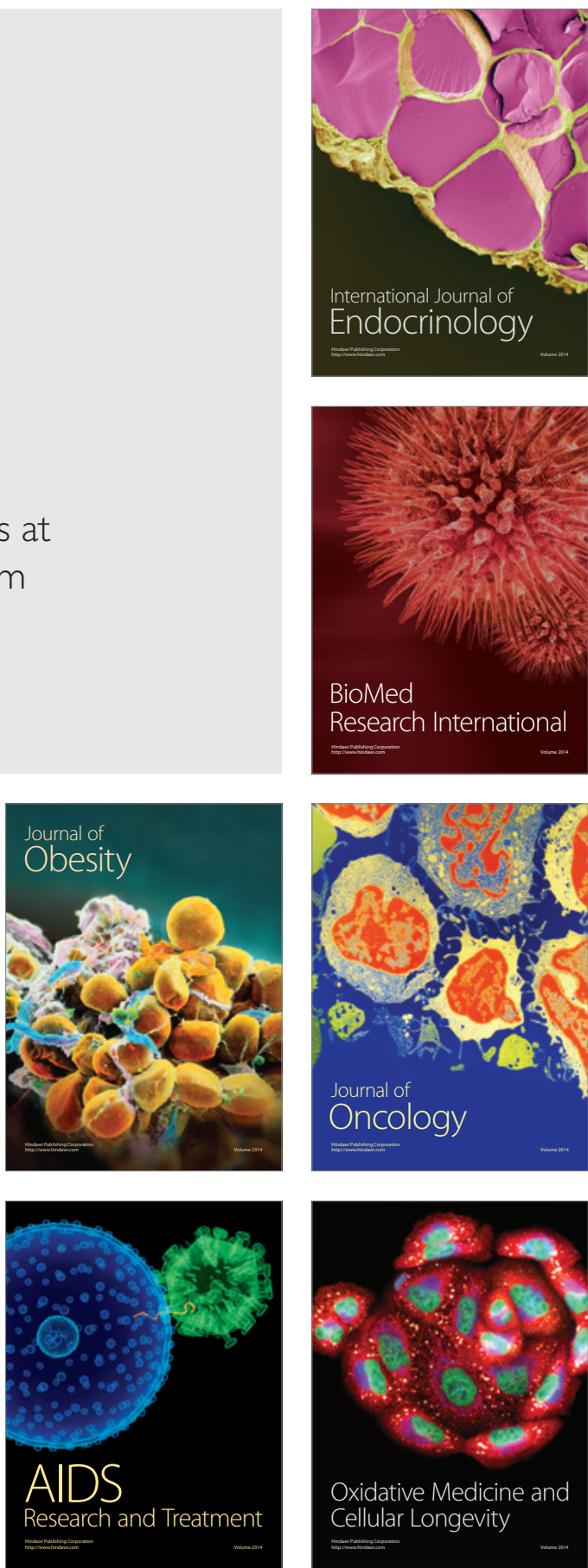